\title{
The coming thaw
}

\author{
Communities around the Arctic are already seeing the effects of melting permafrost. Some of the \\ biggest effects of this thaw will probably emerge in the coming centuries.
}

Arctic warming recently made headlines as anthrax spores from either animal carcasses or shallow graveyards that were previously frozen in permafrost were released across Siberia, killing one child and suspected in the hospitalization of dozens of others. The reindeer herds this community relies on have also been infected ${ }^{1}$. Across the Arctic, infrastructure is threatened by shifting ground, with massive repair costs generated each season. We are pleased to present with this issue a web focus on permafrost (http://www.nature.com/ngeo/ focus/permafrost/index.html) that shows that there are also longer-term threats frozen in the soil.

Approximately $24 \%$ of land in the Northern Hemisphere is underlain by permafrost containing an estimated $1,700 \mathrm{Pg}$ of carbon ${ }^{2}$. This frozen carbon includes, for example, the poorly buried reindeer carcass that has been suggested as a possible source of the anthrax outbreak. While frozen, this material is protected from microbes. However, upon melting, this carbon can be quickly consumed and converted to carbon dioxide or methane. There is evidence that microbial cycling of thawing organic matter is already occurring: Arctic rivers are carrying large amounts of dissolved carbon dioxide created by microbial respiration. As a result, ocean shelf waters around the Arctic are becoming more acidic during summer months ${ }^{3}$. More methane is trapped in the permafrost underneath the continental shelf around the Arctic Ocean, it is currently bubbling to the surface at a rate of roughly $7 \mathrm{Tg} \mathrm{yr}^{-1}$ (ref. 4).

It is less clear whether carbon dioxide and methane emissions are increasing at a pace that is likely to affect current climate change. At the moment, it does not seem like they are. As noted on page 679 of this issue, over the past 60 years, ponds and lakes forming where Arctic permafrost has melted have released between 0.2 and 2.5 Pg of carbon in the form of methane to the atmosphere. This methane comes from organic matter that was frozen in permafrost for hundreds to thousands of years. However, the rate of conversion of this ancient carbon to methane has not measurably increased over the sixty-year study period. This finding is backed up by satellite studies of methane emissions as

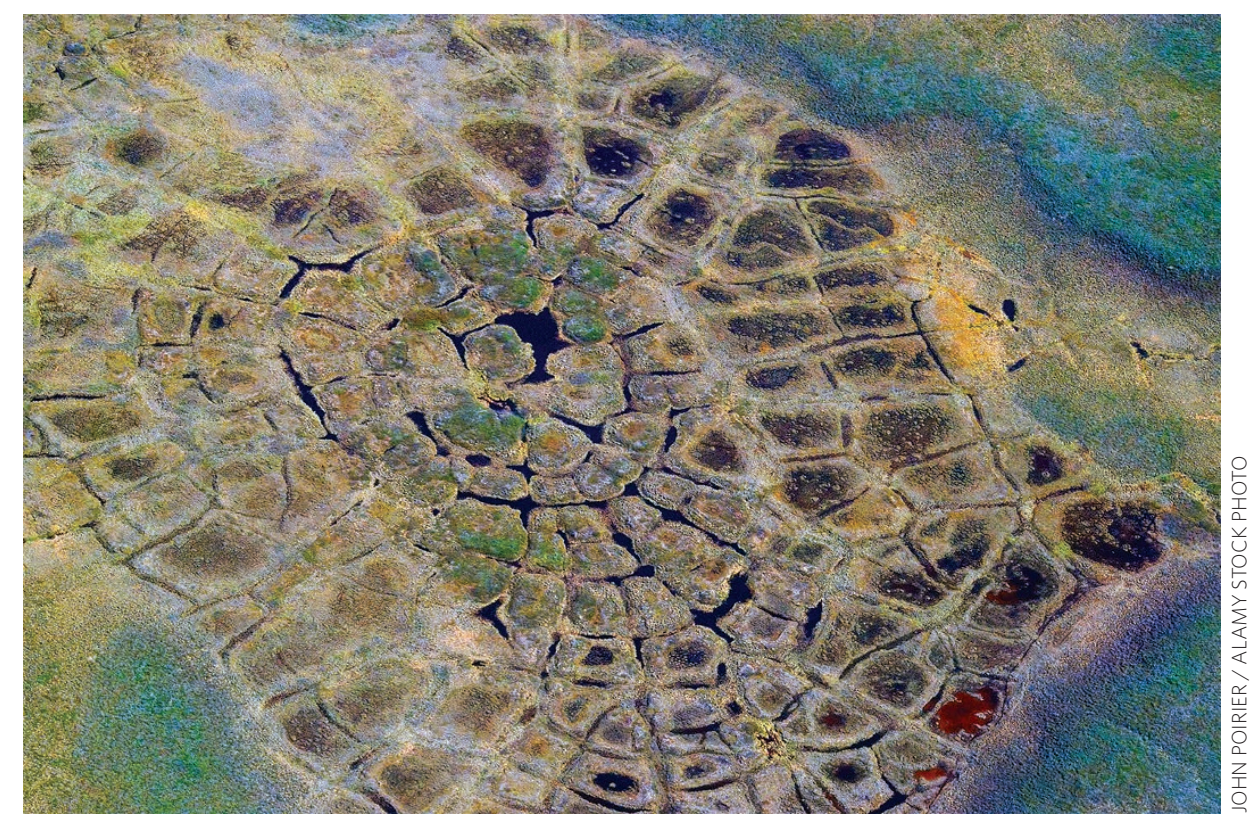

well as methane inventories, none of which suggest substantial increases in methane emissions from the Arctic tundra ${ }^{5-7}$.

But this does not mean that permafrost cannot enhance climate change. As shown on page 683 of this issue, permafrost carbon emissions did play an important part in the rise in atmospheric carbon dioxide concentrations - and hence climate warming - during the last deglaciation. The effect was particularly important between 17,500 and 15,000 years ago, when the amount of solar radiation that reached the high northern latitudes during summer months increased due to changes in the Earth's orbit. Simulations made with the same model show that projected warming is sufficient to trigger permafrost melt and carbon release, but only over timescales of several centuries.

A multi-century timescale for permafrost feedbacks is consistent with current projections and expert assessments, which suggest little role for permafrost carbon release in twenty-first century climate change $e^{5,6}$. Instead, the degradation of permafrost and carbon release is expected to ramp up throughout the twenty-first and twenty-second centuries. By 2300, permafrost could release up to $400 \mathrm{Pg}$ of carbon, primarily as methane $e^{2,8}$. For comparison, fossil-fuel burning currently releases about $8 \mathrm{Pg}$ of carbon into the atmosphere every year, which would add up to well over $2,000 \mathrm{Pg}$ of carbon emitted by 2300 , if current rates of emissions continue unchecked (and fossil fuel supplies go that far). If such massive amounts of emissions do in fact occur, permafrost carbon emissions will be but a minor player in a much larger climate catastrophe. Under more moderate emissions scenarios, however, permafrost carbon may be a comparatively more substantial threat.

From the last deglaciation we can infer that permafrost carbon, once melting, can be instrumental in shifting climate to a warmer state. At the moment, the damaging effects of melting permafrost are mostly limited to the communities that call this frozen ground home. This may not be the case on timescales of centuries, particularly if the thaw continues unchecked.

\footnotetext{
References

1. Luhn, A. Anthrax outbreak triggered by climate change kills boy in Arctic Circle. The Guardian (1 August 2016); http://go.nature. com/2aXfqie

2. Schuur, E. A. G. et al. Climatic Change 119, 359-374 (2013).

3. Semiletov, I. et al. Nat. Geosci. 9, 361-365 (2016).

4. Shakhova, N. et al. Science 327, 1246-1250 (2010).

5. Schaefer, H. et al. Science 352, 80-84 (2016).

6. Sweeney, C. et al. Geophys. Res. Lett. 43, 6604-6611 (2016).

7. Kirschke, S. et al. Nat. Geosci. 6, 813-823 (2013).

8. Schuur, E. A. G. et al. Nature 520, 171-179 (2015).
} 